\title{
Perception, Awareness, Knowledge, Attitude and Practices of Prevention, Control and Management of HIV and AIDS Amongst Online Persons Seeking Sexual Partners in Kenya
}

\author{
Naomi Kinya Miriti ${ }^{1,}$, Sichangi Kasili ${ }^{1}$, Wycliffe Wanzala ${ }^{2,3}$ \\ ${ }^{1}$ Department of Life Sciences, School of Pure and Applied Sciences, South Eastern Kenya University, Kitui, Kenya \\ ${ }^{2}$ Department of Biological Sciences, School of Science and Information Sciences, Maasai Mara University, Narok, Kenya \\ ${ }^{3}$ The Institute of Ethnobiology and Ethnomedicines, Maasai Mara University, Narok, Kenya
}

Email address:

naomimiriti@yahoo.com (N. K. Miriti)

${ }^{*}$ Corresponding author

\section{To cite this article:}

Naomi Kinya Miriti, Sichangi Kasili, Wycliffe Wanzala. Perception, Awareness, Knowledge, Attitude and Practices of Prevention, Control and Management of HIV and AIDS Amongst Online Persons Seeking Sexual Partners in Kenya. Science Journal of Clinical Medicine. Vol. 9, No. 2, 2020, pp. 26-33. doi: 10.11648/j.sjcm.20200902.12

Received: September 18, 2019; Accepted: February 14, 2020; Published: May 28, 2020

\begin{abstract}
The current study was carried out to assess the level of perception, awareness, knowledge, attitude and practice (PAKAP) towards HIV and AIDS scourge amongst sexually active online partners through Nation Media Company in Kenya. The data obtained from 820 advertisements (equivalent to 820 field respondents) while considering their educational levels, age, ethnicity, socio-economic backgrounds etc were utilized. The Pearson Chi-Square and Fisher's Exact Tests were used to analyze data. Results showed that persons involved had a statistically significant perception towards HIV and AIDS ( $p<0.05$ ). Knowledge and awareness of HIV and AIDS were significant by level of education and economic status and not by gender, age, marital status, type of relationship sought and getting children before marriage. Attitude towards HIV and AIDS was significant by level of education $(\mathrm{p}<0.05)$ and not by gender, age, economic status, marital status, type of relationship sought and getting children before marriage $(\mathrm{p}>0.05)$. Practices to manage, control and prevent HIV and AIDS were significant by gender $(\mathrm{p}=0.01)$ and not by age, level of education, economic status, marital status, type of relationship sought and getting children before marriage $(p>0.05)$. Since the results indicated PAKAP was significant $(p<0.05)$, efforts should be made by all stakeholders in HIV and AIDS management, control and prevention programmes to equally target persons dating through social media in order to have a wider coverage for this kind of dating is increasingly becoming the most common practice amongst the sexually active group.
\end{abstract}

Keywords: Human Immunodeficiency Virus, Acquired Immune Deficiency Syndrome, Sexual Partners, Epidemiology, Kenya

\section{Introduction}

Acquired Immunodeficiency Syndrome (AIDS) is one of the most complex health problems of the 21 st century in its fourth decade and has become a pandemic that threatens the world population [22]. Moreover, with no vaccine and/or treatment or cure the disease may continue spreading at an alarming rate [21]. Globally, an estimated 36.9 million people live with HIV [22]. Over $90 \%$ of these individuals are concentrated in the developing countries, mostly in countries least able to sustainably afford to care for infected people.
Sub-Saharan Africa remains the region most heavily affected by HIV worldwide, accounting for over two thirds (67\%) of all people living with HIV and for nearly three quarters (72\%) of AIDS-related deaths by 2010 [21].

The number of people living with HIV in Kenya includes about 1.1 million adults between 15 and 49 years, another 60,000 persons from 50 years of age and over, and approximately 120,000 children [21]. Urban populations have higher adult HIV prevalence (10\%) compared with rural populations [21]. Since HIV weakens the host's immune system, associated opportunistic diseases such as tuberculosis 
and malaria have had to put a strain on health sector in terms of their treatment and management [9]. The Kenya government has employed among strategies, public education to prevent new HIV infections and provision of Antiretroviral to ensure that less damage is inflicted on the immune system and delay the onset of AIDS. Antiretroviral also reduce the impact of HIV transmission in the community (epidemiological goal) and improve the quality of lives [17]. The government has also increased access through provision of free basic education, increase in academic institutions among others. Education in itself is therefore an important tool in combating HIV and AIDS.

The use of online dating sites and mobile dating applications is on the rise, with $15 \%$ of adults having reported use of at least one of these in 2016 [11]. Two thirds of those who participate in online dating report going on a date with someone that they had met through online dating platforms in 2015, up from $43 \%$ in 2005 [24]. The Internet now affords access to a vastly wider network of potential partners who would have been unknown or inaccessible in former eras. Recognizing the unique possibilities afforded by the internet, numerous commercial web sites have arisen to provide these services to users seeking romantic relationships.

Although, a number of studies have explored various aspects of HIV and AIDS, there is no systematic study carried out to evaluate the level of HIV and AIDS knowledge, awareness, attitudes and perception or practices of men and women seeking partners or spouses in Kenya through online or media platforms. One pertinent statement is whether or not teachers and advocates of HIV and AIDS awareness are achieving the intended goals and/or objectives.

\section{Materials and Methods}

\subsection{Human Subjects as Respondents in the Survey Study: The Choice of Study Method}

This study survey was designed to use secondary data and not primary data due to the nature of the sensitivity of the study and henceforth the anticipated unreliability of the data were they to be obtained directly from the target human subjects. By considering the target areas of survey study, the choice of sexual partners and HIV and AIDS, which is associated with traumatic events, mental illness (depression, anxiety, and posttraumatic stress disorder), lack of trust in the healthcare system and government; and experiences of stigma among individuals with HIV disease [3, 24] as sensitive issues in the society, an indirect method of survey using secondary information was innovatively and intelligently sought and adopted as the most appropriate and worthwhile. The soul mate information of advertisements published and made available for public use online and in the Saturday Magazine, Life and Styles, Soul mate column of Nation Media Group Limited by sexually active persons seeking sexual partners of all categories and levels were utilized as the main sources of information for the survey. The secondary information obtained was converted into secondary data sets for analysis.

\subsection{Study Design}

The data were collected for a period of one year and eight months. Every Saturday of the week a Daily Nation Newspaper was obtained and information advertised at Soul mate section of Life and Style Magazine. Every piece of information on one person advertisement was considered as one entry equivalent to a response from an interviewee in the field. The information on the advertisement was translated and transcribed where possible and fed into an excel spread sheet putting into consideration the interviewee's description and that of his/her intended spouse and/or partner regarding: sex, age, height, colour, social life, ethnicity, education, economic status, marital status, societal status, social welfare status, health status, HIV and AIDS status, sexual orientation, geographical location, professionalism, moral values, religion, type of sexual relationship, sensitivity levels towards HIV and AIDS, fertility status, type of advert: through an individual or an agency and method of contacting the candidate spouse and/or partner. Data entered in MS Excel was then imported into a Statistical Products and Service Solutions (SPSS version 21 for Windows) database for analysis sheet. The information available in public domain therefore partly authentic, reliable, truthful and unbiased. Data obtained as key indicators was used for Identification of perception, awareness, knowledge, attitude and practice (PAKAP) from the information given out by clients of Nation Media Group Limited in particular and/or social companies/organizations to help look for partners, friends and/or spouses.

\subsubsection{Sampling Technique}

No normal random sampling was able to fit this particular survey study other than purposive sampling (judgmental, selective, or subjective sampling) because not every advertisement made had the relevant information needed in the survey study, that is, information addressing perception, awareness, knowledge, attitude and practice of control, prevention and management on HIV and AIDS as one seeks appropriate sexual partner (s).

The type of purposive sampling therefore considered for this particular survey study was heterogeneous for its diverse nature in time and space. A diverse range of sexually active human subjects with relevant information addressing PAKAP of control, prevention and management of HIV and AIDS in their advertisements were considered so as to provide as much insight as possible into the survey study.

\subsubsection{Sample Size Determination}

In a year, there are different seasons with different dating needs and demands, which keep on repeating, either within a year or in the following year. For instance, the current Kenyan education system provides for three major holidays (Republic of Kenya, 2010) in a year for a considerably large sexually active population and a time where promises and fulfillment of dating takes place. The implication of this therefore is that dating as a process peaks during these holidays and subsides during the end of the holidays. 
Nevertheless, the advertisements for online and media house dating takes place throughout the year with considerable fluctuations punctuated by these holidays [24, 20, 25, 3]. In any one given Saturday Magazine of Nation Media Group Limited of any week, the number of advertisements made ranged from 12 to 20 . Worth noting and considering was the fact that not every advertisement made in the Saturday Magazine as a response was useful and henceforth utilized in the survey study. Only those advertisements with the most relevant information to address perception, awareness, knowledge, attitude and practice of control, prevention and management of HIV and AIDS were considered worthwhile for incorporation in to the survey study. On average therefore, only 10 advertisements were considered per week so that this number of advertisements was to allow a long period of time to be considered for coverage with a view to collecting data, which must be sufficient to allow evaluation of trends of sexual behaviours if any in the use of social media for online dating with ultimate objective of obtaining information that can be useful to policy makers. It therefore followed with logical necessity that the research study covered one year with 52 weeks and different seasons that allowed dating and fulfillment of sexual promises in order to evaluate any trends of sexual behaviour amongst the online and media partner and/or spouse seekers. To further understand these trends, data collection of the survey study extended into the following year, thus covering an extra 30 weeks, totaling to 82 weeks for the entire research period for data collection. The sample size therefore became $10 \times 82=$
820 advertisements (which is equivalent to 820 normal field survey respondents).

\subsubsection{Data Management and Analysis}

Data were entered in MS Excel spreadsheets and thereafter exported to SPSS statistical spread sheet for analysis. Descriptive statistics in form of tables and graphs were used to show the nature of the population under study and relationships between different variables. Inferential statistics involved data analysis using Pearson Chi-square and Fisher's exact tests. All analyses were done at $\alpha=0.05$ significance level.

\section{Results}

\subsection{Profiles of the Respondents}

Among the 820 sexually active respondents (equivalent to the owners of the advertisements made in Saturday Magazine of Nation Media Group Limited in Kenya, East Africa) were heterogeneously selected comprising 53\% (434 respondents) females and 47\% (386 respondents) males (Table 1). Further, the Table 1 provides detailed information on the nature of the respondents regarding their age, economic status, level of education, marital status, child factor in one's life and finally, the type of relationship sought. Most of the respondents were unmarried non-graduates within the age brackets of 36-45 with unstable economy, henceforth, looking forward to develop a relationship that can lead to marriage.

Table 1. A description of the profiles of respondents and the type of sexual relationships they seek to establish $(N=820)$.

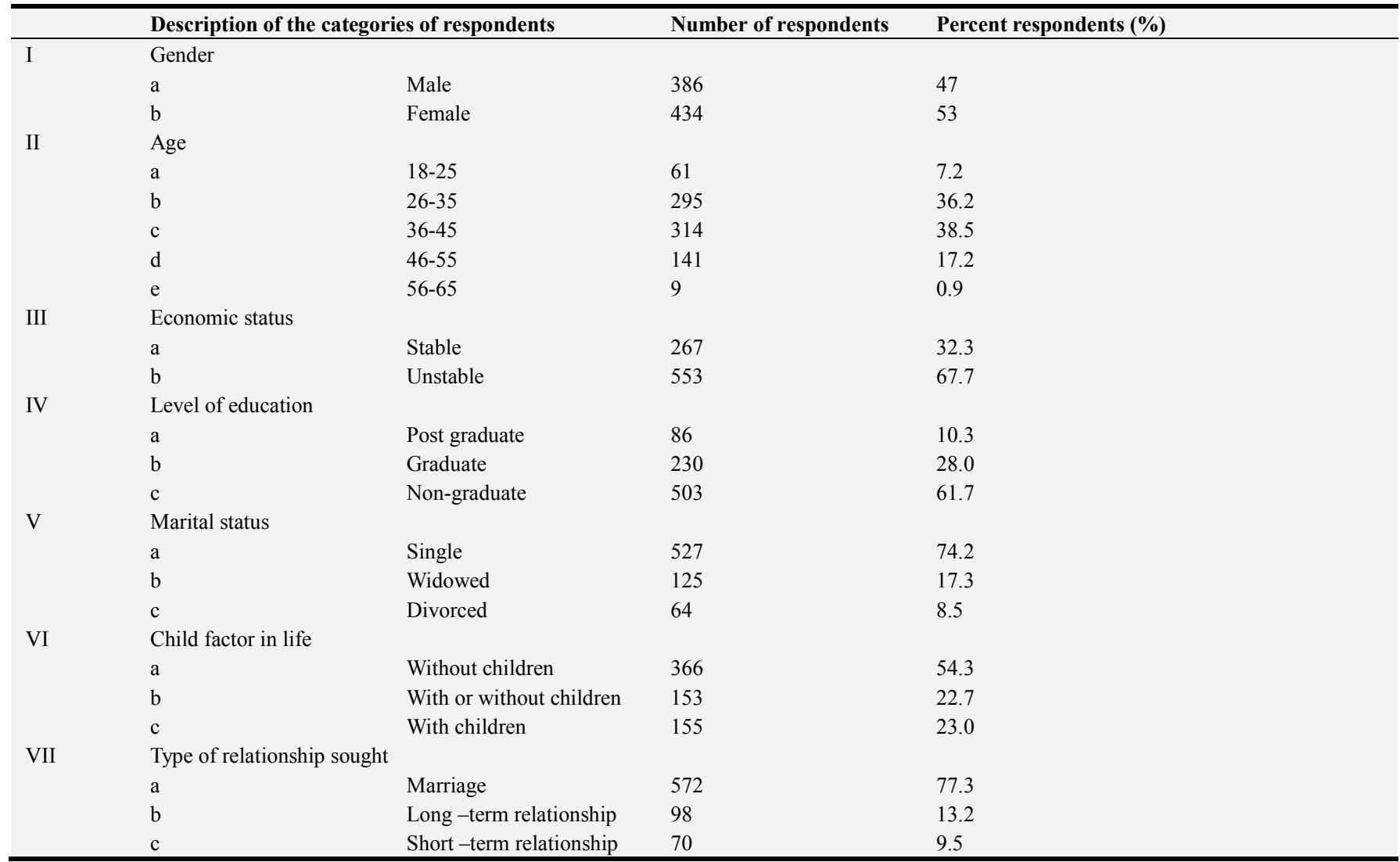




\subsection{The Level of Awareness, Knowledge, Attitude and Practice of Control, Prevention and Management of HIV and AIDS When Seeking Partner and/or Spouse}

\subsubsection{Awareness of HIV and AIDS}

There was significant difference between the respondents who showed HIV and AIDS awareness and respondents who did not show HIV and AIDS awareness when seeking partner $\left(\chi^{2}=22.168 ; \mathrm{df}=1 ; \mathrm{p}=0.000\right)$. Among the total respondents, $58.3 \%$ (472 respondents) were aware of HIV and AIDS, while $41.7 \%$ (338 respondents) were not aware of HIV and AIDS.

\subsubsection{Awareness of HIV and AIDS by level of Education}

The level of education showed significant difference in HIV and AIDS awareness among the respondents seeking partner $\left(\chi^{2}=73.372 ; \mathrm{df}=2 ; \mathrm{p}=0.00\right)$. Of the respondents who showed HIV and AIDS awareness, $49.6 \%$ were nongraduate, $35.6 \%$ graduate and $14.8 \%$ postgraduate. Among the respondents who never showed HIV and AIDS awareness, $78.7 \%$ were non-graduate, $17.5 \%$ graduate and $3.8 \%$ postgraduate. Among the non-graduate respondents, $46.8 \%$ were HIV and AIDS aware, while $53.2 \%$ were not aware. Seventy four percent of the graduate respondents showed HIV and AIDS awareness, while 26\% never showed awareness. Among the postgraduate respondents, $84.3 \%$ showed awareness toward HIV and AIDS, while $15.7 \%$ did not show awareness (Figure 1).

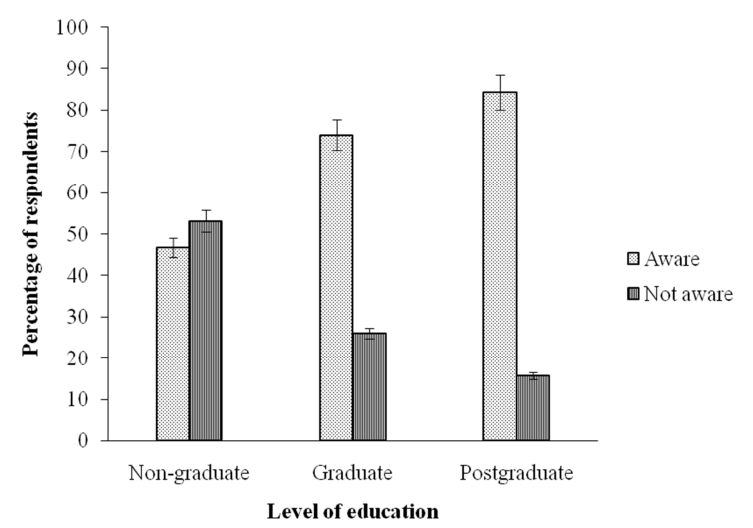

Figure 1. Awareness of HIV and AIDS by level of education amongst respondents seeking partners in Kenya.

\subsubsection{Awareness of HIV and AIDS by Economic Status}

The economic status of the respondents seeking partner demonstrated significant difference in HIV and AIDS awareness. $\left(\chi^{2}=4.122 ; \mathrm{df}=1 ; \mathrm{p}=0.04\right)$. Among the respondents who showed HIV and AIDS awareness, 35.2\% were economically stable, while $64.8 \%$ were economically unstable. Of the respondents who never exhibited HIV and AIDS awareness, $28.4 \%$ economically stable, while $71.6 \%$ economically unstable. Of the respondents who were economically stable, $63.4 \%$ showed awareness towards HIV and AIDS, while $36.6 \%$ did not show awareness. Among the economically unstable respondents, 55.8\% exhibited HIV and AIDS awareness, while $44.2 \%$ did not show awareness (Figure 2).

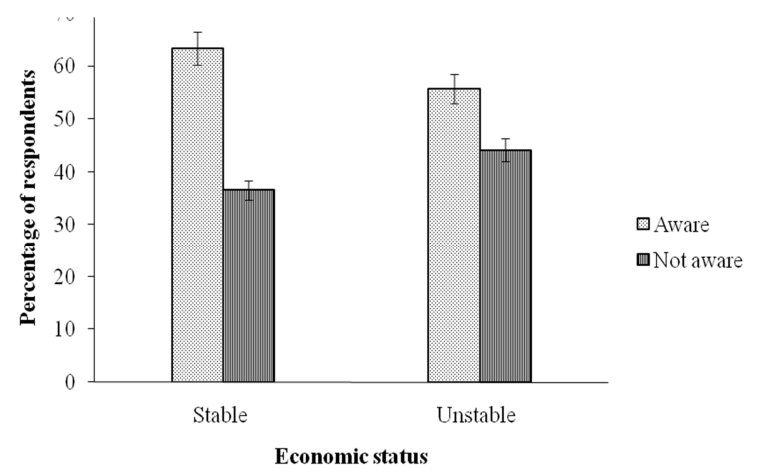

Figure 2. Awareness of HIV and AIDS by Economic status amongst respondents seeking partners in Kenya.

\subsection{Knowledge of HIV and AIDS}

The respondents who had HIV and AIDS knowledge and those who did not have HIV and AIDS knowledge were significantly different when seeking a partner $\left(\chi^{2}=9.131 ; \mathrm{df}\right.$ $=1 ; \mathrm{p}=0.00$ ). The respondents who had HIV and AIDS knowledge were at $55.3 \%$ (448 respondents), while $44.7 \%$ (362 respondents) of the respondents lacked HIV and AIDS knowledge.

\subsubsection{Knowledge of HIV and AIDS by Level of Education}

The level of education showed significant association in terms of HIV and AIDS knowledge among the respondents seeking a partner $\left(\chi^{2}=41.069 ; \mathrm{df}=2 ; \mathrm{p}=0.00\right)$. Among the respondents who had HIV and AIDS knowledge, $54.2 \%$ were non-graduate, $29.9 \%$ graduate and $15.8 \%$ postgraduate. Of the respondents who lacked HIV and AIDS knowledge, 71\% were non-graduate, $25.7 \%$ graduate and $3.3 \%$ postgraduate. Among the non-graduate respondents, $48.6 \%$ had HIV and AIDS knowledge, while $51.4 \%$ lacked HIV and AIDS knowledge. Fifty nine percent of the graduate respondents had HIV and AIDS knowledge, while $41 \%$ of graduate respondents lacked HIV and AIDS knowledge. Among the postgraduate respondents, $85.5 \%$ had HIV and AIDS knowledge, while $14.5 \%$ lacked HIV and AIDS knowledge (Figure 3).

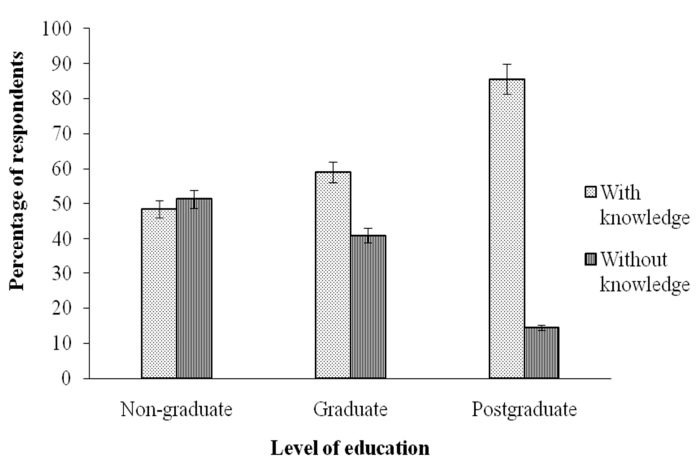

Figure 3. Knowledge of HIV and AIDS by level of education amongst respondents seeking partners in Kenya. 


\subsubsection{Knowledge of HIV and AIDS by Economic Status}

The economic status of the respondents exhibited significant difference in terms of HIV and AIDS knowledge among the respondents looking for a partner $\left(\chi^{2}=3.912\right.$; df $=1 ; \mathrm{p}=0.04)$. Among all respondents who had knowledge about HIV and AIDS, 35.3\% were economically stable while $64.7 \%$ were economically unstable. Of the respondents who had no HIV and AIDS knowledge, 28.7\% were economically stable, while $71.3 \%$ were economically unstable. Of the total respondents who were economically stable $60.3 \%$ had knowledge about HIV and AIDS, while 39.7\% never had HIV and AIDS knowledge. Among the economically unstable respondents, 52.9\% exhibited HIV and AIDS knowledge, while $47.1 \%$ never showed HIV and AIDS knowledge (Figure 4).

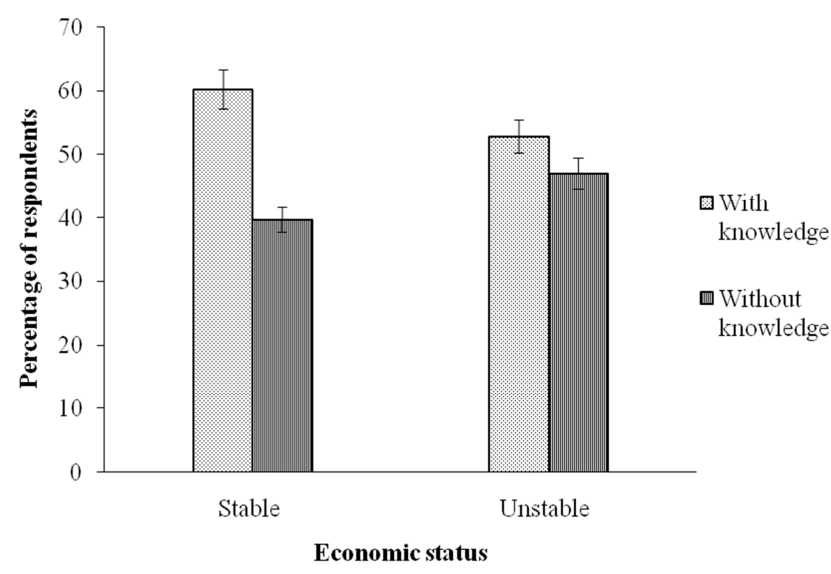

Figure 4. Knowledge of HIV and AIDS by Economic status amongst respondents seeking partners in Kenya.

\subsection{Attitude towards HIV and AIDS}

There was significant difference among the respondents who had a positive attitude and respondents who had a negative attitude towards HIV and AIDS when seeking for a partner $\left(\chi^{2}=17.190 ; \mathrm{df}=1 ; \mathrm{p}=0.00\right)$. The majority of the respondents had positive attitude towards HIV and AIDS at $57.3 \%$, while $42.7 \%$ of the respondents had negative attitude towards HIV and AIDS.

\subsubsection{Attitude Towards HIV and AIDS by Level of Education}

The level of education exhibited significant difference in attitude towards HIV and AIDS among the respondents seeking partner $\left(\chi^{2}=32.204 ; \mathrm{df}=2 ; \mathrm{p}=0.00\right)$. Among the respondents who had positive attitude towards HIV and AIDS, 54.1\% were non-graduate, $31.7 \%$ graduate and $14.2 \%$ postgraduate. Of the respondents who had negative attitude towards HIV and AIDS, $72.0 \%$ were non-graduate, $23.1 \%$ graduate and $4.9 \%$ postgraduate. Among the non-graduate respondents, $50.2 \%$ had positive attitude towards HIV and AIDS, while $49.8 \%$ had negative attitude towards HIV and AIDS. Sixty five percent of the graduate respondents had positive attitude towards HIV and AIDS, while $35 \%$ of graduate respondents had negative attitude towards HIV and
AIDS. Among the postgraduate respondents, 79.5\% had positive attitude towards HIV and AIDS, while $20.5 \%$ had negative attitude towards HIV and AIDS (Figure 5).

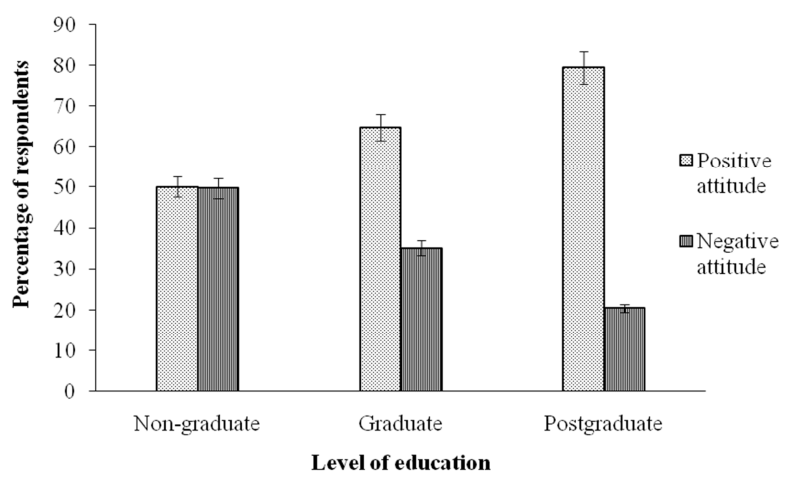

Figure 5. Attitude towards HIV and AIDS by level of education amongst respondents seeking partners.

\subsubsection{Practice of Prevention, Control and Management of HIV and AIDS}

The respondents who practiced and who did not practice against HIV and AIDS were significantly different when looking for a partner $\left(\chi^{2}=50.375 ; \mathrm{df}=1 ; \mathrm{p}=0.00\right)$. Many of the respondents practiced against HIV and AIDS at $62.5 \%$, while $37.5 \%$ of the respondents did not practice toward HIV and AIDS.

\subsubsection{Practices of Prevention, Control and Management of HIV and AIDS by Gender}

There was significant difference in practice against HIV and AIDS by gender among the respondents who were looking for a partner $\left(\chi^{2}=6.114 ; \mathrm{df}=1 ; \mathrm{p}=0.01\right)$. Among the respondents who practiced against HIV and AIDS, $43.7 \%$ were male, while $56.3 \%$ were female. Among the respondents who did not practice towards HIV and AIDS, $52.6 \%$ were male, while $47.4 \%$ were female. The male respondents who practiced towards HIV and AIDS were at $58 \%$, while male respondents who did not practice towards HIV and AIDS were at $42 \%$. The female respondents who practiced towards HIV and AIDS were at $66.4 \%$ and who did not practice were at 33.6\% (Figure 6).

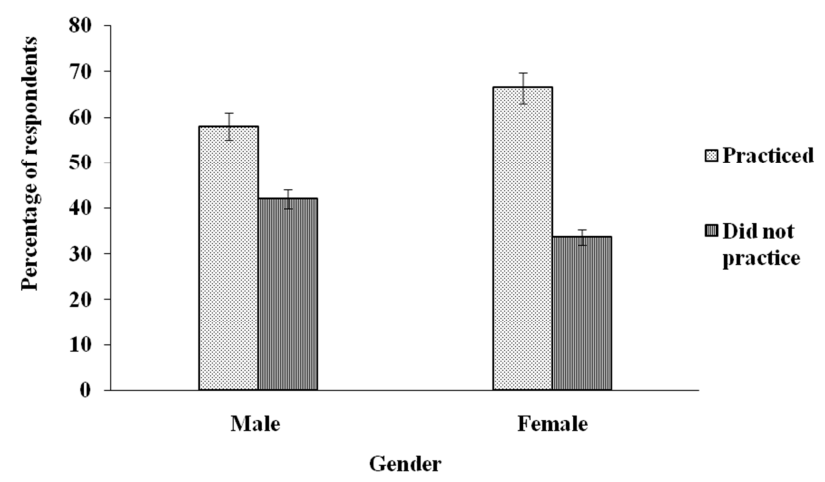

Figure 6. Practices of prevention, control and management of HIV and AIDS by gender amongst respondents seeking partners for sexual relationships in Kenya. 


\section{Discussion}

To achieve the objective of the study, the target cohort population comprised only sexually active persons determined to get the desired partners for sexual satisfaction in a non-threatening environment [11, 14]. More female $(53 \%)$ than male $(47 \%)$ respondents with ages ranging from 18 to 65 were willingly involved in intended engagement into various types of sexual relationships and behaviours, a situation that causes great concern in the society in the era of HIV and AIDS pandemic [8]. Most respondents were economically unstable $(67.7 \%)$, none-graduates $(61.7 \%)$, single $(74.2 \%)$, without children (54.3\%), and hence, sought a type of relationship that would eventually lead to marriage. There is, therefore, an implication that a wide range of complex and mostly, human-based behavioral factors might be involved in determining the epidemiology, incidence and prevalence of the HIV and AIDS pandemic [27]. Nevertheless, the severity of HIV and AIDS epidemic may be more pronounced in less-developed countries, where lower socioeconomic status might be well positioned in the society to determine the impact of the HIV and AIDS epidemic on the target population [26,27].

The findings of the current study indicate that there is a significant level of HIV and AIDS awareness, knowledge, attitude and practices amongst men and women looking for partners and/or spouses in Kenya. Generally, most of the respondents $(58.3 \%)$ were aware of HIV and AIDS while looking for partners and/or spouses of any assessed of the levels. This could be due to the current global mass campaign against HIV and AIDS amongst the sexually active generation seeking partners to establish the desired relationships [19]. In Kenya, the mass campaign has been reinforced by the introduction of HIV and AIDS curriculum in Secondary schools, tertiary colleges and institutions of higher learning (from Ministry of Education, Ministry of Health and UNESCO on HIV and AIDS integrated curriculum development). HIV and AIDS integrated curriculum has addressed the psycho-social impacts associated with the disease such as stigma, fear, depression and shame and has educated communities so that they can accept and understand particularly the rights of those affected by HIV and AIDS [23]. The efficiency and effectiveness of HIV and AIDS curriculum implementation programme that has contributed to the change of behavior amongst the youth delay their initiation into sexual activity and impart skills for self-protection from vulnerability to sex and HIV and AIDS infection [4].

The number of both male and female respondents was not significantly different in terms of HIV and AIDS awareness. The respondents with higher level of education showed significantly better awareness of HIV and AIDS than the respondents with low level of education. The respondents with post graduate education level were most highly aware of HIV and AIDS while looking for sexual partners, followed by graduate respondents and finally the non-graduate respondents in that order. Similar findings have been reported by [2] which showed that respondents with higher level of education were better aware of HIV and AIDS than respondents with low level of education in sub-Saharan Africa. [10] also demonstrated that respondents of graduate level of education were more informed and aware of HIV and AIDS than respondents from secondary and primary schools in Kenya.

The majority of the respondents had significantly sufficient knowledge about HIV and AIDS while seeking sexual partners. There was significant association between higher level of education and good knowledge of HIV and AIDS in respondents looking for sexual partners. Majority of the postgraduate respondents had good knowledge of HIV and AIDS followed by graduate respondents and finally nongraduate respondents. Studies carried out in Botswana and Kenya similarly showed that students with higher level of education had better knowledge of HIV and AIDS than those with low level of education [12]. Similar study findings may have informed the World Bank and World Food Programme support for the supreme importance of education in the control and management of HIV and AIDS [18].

A significantly high number of the respondents had positive attitude towards HIV and AIDS pandemic while seeking sexual partners in Kenya. Positive attitude was indicated by willingness to have a HIV test, and one sexual partner. HIV and AIDS attitudes and practices together with knowledge influences decision and choice making hence reducing the risk of infection, re-infection and transmission of HIV [16]. Responses indicative of positive attitudes, practices and perception from spouse seekers were significant in a number of questions: whether a partner had undergone a HIV test, having one sexual partner and whether it was a good idea looking for a partner with similar HIV status. The differences were associated with having received formal HIV and AIDS education [16]. The current study findings were consistent with an Indian report which showed that senior secondary school children had better attitudes towards HIV and AIDS in Delhi [15]. [1] reported that majority of students in health institutes in Sana'a city had positive attitudes towards HIV and AIDS. However, gender of respondents showed no significant different were in terms of attitude towards HIV and AIDS when looking for a sexual partner. The results of this study showed that as the level of education increases, the negative attitude towards the HIV and AIDS pandemic amongst those seeking sexual partners decreases. The respondents with postgraduate level of education significantly showed better positive attitude towards HIV and AIDS pandemic than those with graduate and non-graduate level of education amongst those seeking sexual partners. [13] also reported that teachers with higher education had a better attitude towards HIV and AIDS pandemic than those teachers with lower level of education in Belize.

A considerably high proportion of the respondents had positive control and management practices towards HIV and AIDS pandemic. The practices noted to exist amongst the respondents included: having only one sexual partner and 
taking a test for HIV. The practices were used to eliminate the chances of contracting HIV. The respondents with nongraduate, graduate and postgraduate levels of education insignificantly showed positive practices towards HIV and AIDS when seeking sexual partners. These findings were in agreement with the study carried out by [5], which reported that male high school students had positive practices towards HIV and AIDS in Lao People's Democratic Republic. The findings also conform to a previous study, which showed that condom use among university student though high, was not consistent [16].

\section{Conclusions}

The current study confirmed that partners/spouse seekers through the media platform had some knowledge, awareness, attitudes, perception and practices about HIV and AIDS when looking for a sexual partner Since the data indicates that there is perception, awareness, knowledge, attitude and practice towards HIV and AIDS, effort should be made by stakeholders in HIV and AIDS prevention and control to equally target persons dating in media and online for even higher gains in tandem with conventional ones because this kind of dating is becoming more and common. Since the cure for HIV and AIDS is nowhere in sight, though the quest for it continues through research, It is recommended that education be accorded the priority it deserves in combating HIV and AIDS on the understanding of the fact that it is controllable, manageable and preventable.

\section{Acknowledgements}

The authors are indebted to the Library Department, South Eastern Kenya University for availing newspapers to carry out this research.

\section{Conflict of Interest}

The authors declare no competing interests.

\section{References}

[1] Al-Rabeei, N. A., Dallak, A. M., \& Al-Awadi, F. G. (2012). Knowledge, attitude and beliefs towards HIV and AIDS among students of health institutes in Sana'a city. Eastern Mediterranean Health Journal, 18 (3), 221.

[2] Baker, D. P., Leon, J., \& Collins, J. M. (2011). Facts, attitudes, and health reasoning about HIV and AIDS: explaining the education effect on condom use among adults in sub-Saharan Africa. AIDS and Behavior, 15 (7), 1319-1327.

[3] Breet, E., Kagee A., Seedat S., (2014). HIV-related stigma and symptoms of post-traumatic stress disorder and depression in HIV-infected individuals: does social support play a mediating or moderating role? AIDS Care. 26 (8): 947-951. doi: 10.1080/09540121.2014.901486. Epub 2014 Mar 26.

[4] Cluver, L. D., Orkin, M. F., Yakubovich, A. R., \& Sherr, L. (2016). Combination social protection for reducing HIV-risk behavior amongst adolescents in South Africa. Journal of acquired immune deficiency syndromes (1999), 72 (1), 96.

[5] Conroy, A. A., McGrath, N., van Rooyen, H., Hosegood, V., Johnson, M. O., Fritz, K.,... \& Darbes, L. A. (2016). Power and the association with relationship quality in South African couples: Implications for HIV/AIDS interventions. Social Science \& Medicine, 153, 1-11.

[6] Conroy, S. J. (2010). Women's Inheritance and Conditionality in the Fight against AIDS. Wis. Int'l LJ, 28, 705.

[7] Cornoy, L., \& de Walque, D. (2007). The determinants of HIV infection and related sexual behaviors: evidence from Lesotho.

[8] Craven, B. M., \& Stewart, G. T. (2012). 10 Public policy and public health: coping with potential medical disaster. What Risk?: Paperback edition, 221.

[9] Kenya, Demographic, Health Survey (KDHS). 2016. Kenya National Bureau of Statistics.

[10] Durojaiye, O. C. (2014). Knowledge, attitude and practice of HIV and AIDS: Behavior change among tertiary education students in Lagos, Nigeria. Annals of Tropical Medicine and Public Health, 4 (1), 18.

[11] Enock, N. (2016). Demographic, Socio-Economic and Psychosocial Determinants of Current and Consistent Condom Use among Adolescents in Botswana. World Journal of AIDS, $6(04), 137$.

[12] Fako, T. T. (2010). The connection between poverty sexual activity knowledge about HIV AND AIDS and willingness to test for HIV infection among young people. European Journal of social sciences, 15 (1), 115-128.

[13] Gayle, H. D., Keeling, R. P., Garcia-Tunon, M., Kilbourne, B. W., Narkunas, J. P., Ingram, F. R., \& Curran, J. W. (2012). Prevalence of the human immunodeficiency virus among university students. New England Journal of Medicine, 323 (22), 1538-1541.

[14] Irungu, T. K., Varkey, P., Cha, S., \& Patterson, J. M. (2008). HIV voluntary counselling and testing in Nakuru, Kenya: findings from a community survey. HIV medicine, 9 (2), 111117.

[15] Kabiru, C. W., \& Orpinas, P. (2009). Factors associated with sexual activity among high-school students in Nairobi, Kenya. Journal of adolescence, 32 (4), 1023-1039.

[16] Kasili, S., Kisangau, D. P., \& Kimatu, J. (2016). Mainstreaming of HIV and AIDS in Kenyan University Academic Programmes: Impact on Students' Sexual Behaviour, South Eastern Kenya University (Unpublished data).

[17] Jukes, M., Simmons, S., \& Bundy, D. (2008). Education and vulnerability: the role of schools in protecting young women and girls from HIV in southern Africa. Aids, 22, S41-S56.

[18] Mupa, P. (2012). Quality Assurance in the Teaching and Learning of HIV and AIDS in Primary Schools in Zimbabwe (Doctoral dissertation).

[19] Mwamwenda, T. S. (2014). Education level and human immunodeficiency virus (HIV)/acquired immune deficiency syndrome (AIDS) knowledge in Kenya. Journal of AIDS and HIV Research, 6 (2), 28-32. 
33 Naomi Kinya Miriti et al:: Perception, Awareness, Knowledge, Attitude and Practices of Prevention, Control and Management of HIV and AIDS Amongst Online Persons Seeking Sexual Partners in Kenya

[20] Nation Media Group, (2009). Life and Styles: Soulmate, Saturday Magazine, Nation Media Group. http://www.nation.co.ke/lifestyle/saturday/1216-525698p0fode/index.html as retrieved on Thursday, December 29th, 2016 at 6:40PM East Africa Time.

[21] National AIDS Control Council (NACC) Kenya AIDS Epidemic: Update 2016. Nairobi, Kenya. [22] UNAIDS, 2016 Report on the Global HIV and AIDS Epidemic

[22] United Nations Children's Fund (UNICEF). 2016. Levels and Trends in Child Mortality Report 20164. New York: UNICEF

[23] Whetten, K., Reif, S., Whetten, R., Murphy-Mcmillan, L. K., (2008). Trauma, Mental Health, Distrust, and Stigma Among HIV-Positive Persons: Implications for Effective Care. Psychosomatic Medicine 70:531-538.
[24] Thottam, I., (2014). The history of online dating. http://www.eharmony.com/history-of-online-dating/ as retrieved on Thursday, December 29th 2016, at 12:57 East Africa Time.

[25] Smith, A. W., Duggan, M. (2013). Online Dating \& Relationship. Washington, DC: Pew Research Center.

[26] Mertens, T. E., \& Low-Beer, D. (1996). HIV and AIDS: where is the epidemic going?. Bulletin of the World Health Organization, 74 (2), 121.

[27] Lou, L. X., Chen, Y., Yu, C. H., Li, Y. M., \& Ye, J. (2014). National HIV/AIDS mortality, prevalence, and incidence rates are associated with the Human Development Index. American journal of infection control, 42 (10), 1044-1048. 